\title{
Spatial and temporal variations on the coexistence of Aedes and Culex larvae in Southern Thailand
}

\author{
Anantanit Chumsri - Mullica Jaroensutasinee (D. Krisanadej Jaroensutasinee iD
}

\author{
A Chumsri - M Jaroensutasinee (Corresponding author) • \\ K Jaroensutasinee \\ Centre of Excellence for Ecoinformatics, School of Science, \\ Walailak University, 222 Thaiburi, Thasala, Nakhon Si \\ Thammarat 80161, Thailand.
}

\author{
Received: June 07, 2020 • Accepted: June 25, 2020 • Published Online: July 10, 2020
}

\begin{abstract}
This study investigated spatial and temporal variations on the coexistence of Aedes aegypti, Aedes albopictus, and Culex larvae in five subdistricts in Nakhon $\mathrm{Si}$ Thammarat, Thailand. We tested two main hypotheses on the spatial and temporal coexistence of mosquito larvae: (1) condition-specific competition and (2) spatial variation among the five subdistricts. We compared the number of positive houses, positive containers, mosquito coexistence during both the wet and dry seasons. The results showed that from a total of 1,072 positive containers collected in both seasons, Ae. albopictus larvae were found in the highest number of containers (745 containers), followed by containers with Ae. aegypti larvae (283 containers) and containers with Culex larvae (254 containers). During the wet season, there were higher numbers of positive houses, positive containers, and containers with only Ae. albopictus larvae than during the dry season. On the other hand, during the dry season when the water containers were very scarce, there were higher numbers of containers with Culex larvae, and containers held more than one type of mosquito larvae. This indicates that both temporal and spatial variations may contribute to the local coexistence of Aedes and Culex mosquito larvae species in Lansaka District areas in Thailand.
\end{abstract}

Keywords: Nakhon Si Thammarat, positive containers, positive house, wet and dry season

\section{Introduction}

Competitive interactions between two mosquito species are often asymmetrical and may have important consequences on mosquito-borne infections and control strategies (Juliano 2009). One species can be inferior to another species but at the same time superior to others. The competitive asymmetry has been attributed to efficiency in converting food to biomass, larval food substrates (Barrera 1996; Daugherty et al 2000; Braks et al 2004), larval density
(Juliano et al 2004; Serpa et al 2008), and temperature (Carrieri et al 2003). For example, Ae. aegypti proves to be the inferior competitor to Ae. albopictus but superior to $C x$. quinquefasciatus (Santana-Martínez et al 2017) and $C x$. pipiens (Francia and Maciá 2017). Ae. albopictus is a competitively superior species against other mosquito species, such as Ae. aegypti (Barrera 1996; Daugherty et al 2000; Murrell and Juliano 2008; Serpa et al 2008), Ae. japonicus (Armistead et al 2008), Ae. triseriatus (Ho et al 1989; Novak et al 1993), Cx. coronator (Yee and Skiff, 2014), and $C x$. pipiens (Carrieri et al 2003, 2011; Costanzo et al 2005; Muturi et al 2011).

Asymmetrical competition only occurs when the potential competitors encounter one another in nature. With high competitive asymmetry, the competitively inferior species is expected to shift their temporal patterns to lower interspecific competition. For example, $C x$. pipiens is the inferior species to Ae. albopictus, and it displays a time shift to reduce the overlapping period in the US (Costanzo et al 2005) and Italy (Carrieri et al 2003; Marini et al 2017). In Thailand, Ae. aegypti is the inferior species to Ae. albopictus, and it also displays a time shift resulting in the greatest prevalence during the dry season instead of the wet season when Ae. albopictus is most prevalent (Preechaporn et al 2006, 2007; Chumsri et al 2018).

Aedes and Culex larvae are the most widespread mosquito larvae in Thailand (Scanlon and Esah 1965; Chansang et al 1999; Chareonviriyaphap et al 2003; Luemoh et al 2003; Thavara et al 2004; Thanispong et al 2008; Preechaporn et al 2007; Wongkoon et al 2007; Chumsri et al 2018; Promprao et al 2018). In Thailand, Ae. aegypti, Ae. albopictus, and Culex spp. encounter one another in their shared water containers with overlapping distribution, but they prefer different breeding sites (Preechaporn et al 2007; Wongkoon et al 2007; Chumsri et al 2018; Promprao et al 2018). Their breeding site preferences could be shaped by both 
interspecific competition and spatial and temporal niche differentiation. Ae. aegypti prefers clean indoor water containers, whereas Ae. albopictus prefers outdoor artificial water containers containing a greater amount of organic debris (Chareonviriyaphap et al 2003; Preechaporn et al 2007; Wongkoon et al 2007; Chumsri et al 2018), while Culex larvae inhabit outdoor containers with high levels of organic matter and highly contaminated bodies of water, such as drainage sewers from houses (Preechaporn et al 2007).

Our study, investigating the coexistence of Ae. aegypti, Ae. albopictus, and Culex larvae in five subdistricts (Khaokaew, Lansaka, Thadi, Kamlon, and Khunthale) in Nakhon Si Thammarat, southern Thailand during the wet and dry seasons, was based on two main hypotheses: (1) Condition-specific competition predicts that (1a) all species would occupy a greater proportion of containers and be more abundant during the wet season than during the dry season; (1b) the abundance of Ae. albopictus larvae would be higher during the wet season (October-December), and the abundance of Ae. aegypti and Culex larvae would decrease; and (1c) Ae. albopictus larvae would be more competitive compared to Ae. aegypti and Culex larvae, and thus, Ae. albopictus larvae would be present in more containers. (2) The spatial hypothesis predicts that (2a) co-occurrence of larval species would be found in different subdistricts; and (2b) Ae. albopictus larvae would be more competitive compared to Ae. aegypti and Culex larvae in most of the subdistricts.

To the best of our knowledge, this is one of the first efforts to assess the coexistence and interactions of $A e$. aegypti, Ae. albopictus, and Culex larvae.

\section{Materials and Methods}

Study site

This study was conducted in five subdistricts (Lansaka, Khaokaew, Thadi, Kamlon, and Khunthale) in Lansaka District, Nakhon Si Thammarat Province, in the southern part of Thailand $\left(8.40700^{\circ} \mathrm{N}\right.$ and $99.76891^{\circ} \mathrm{E}$ ) (Figure 1a-c). The dry season in Nakhon Si Thammarat is from February to May. The wet season starts in June and ends in January. Over 10 years, (2009-2018), the annual mean temperature was about $27.44{ }^{\circ} \mathrm{C}$. The average maximum and minimum temperatures were $35.02{ }^{\circ} \mathrm{C}$ and $21.99^{\circ} \mathrm{C}$, respectively. The mean monthly rainfall during the wet season was $340.44 \mathrm{~mm}$. During the dry and wet seasons, mean temperatures were approximately $27.94{ }^{\circ} \mathrm{C}$ and $26.95{ }^{\circ} \mathrm{C}$, respectively (collected by the Centre of Excellence for Ecoinformatics, Walailak University).

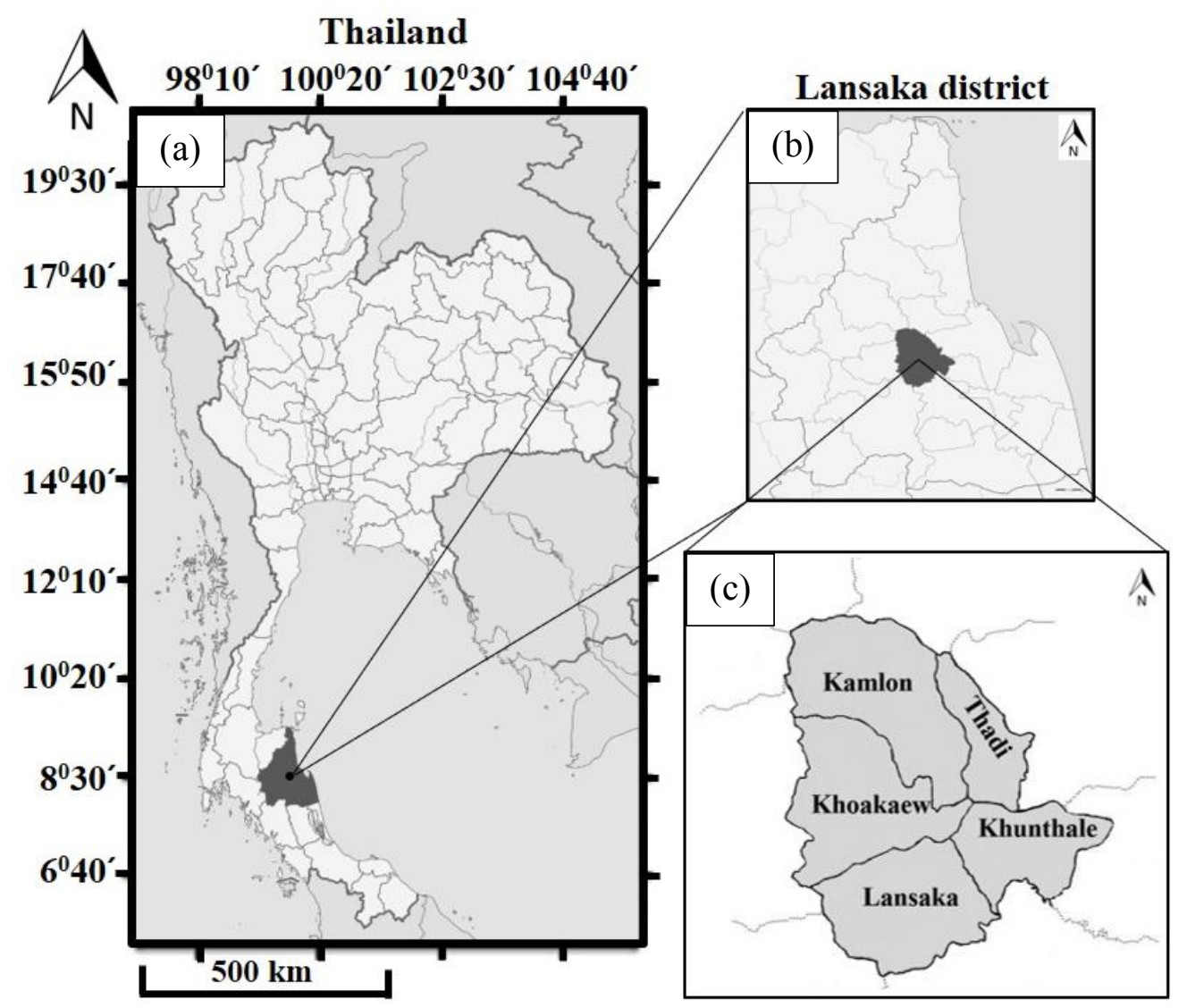

Figure 1 (a) Map of Thailand and black dot represents location of Lansaka District, Nakhon Si Thammarat Province, Southern Thailand, (b) Lansaka District, and (c) the study areas of five subdistricts )Lansaka, Khaokaew, Thadi, Kamlon, and Khunthale). 


\section{Mosquito larvae collection}

In each subdistrict, 120 houses were randomly selected to study breeding sites of Aedes and Culex mosquitoes during the dry (March-April, 2018) and wet (October-December, 2018) seasons. There were a total of 300 households sampled during the dry season. The same 300 households were resampled during the wet season to compare the differences in the number of Ae. aegypti, Ae. albopictus and Culex larvae in water containers between seasons and among subdistricts.

In each house, mosquito larvae were collected based on the GLOBE Mosquito Protocol (www.globe.gov, 2018) from different kinds of water containers (e.g., water-storing containers - water jars, water tanks, water buckets, etc.; plant pots; feeding pans of animals; lids of water containers; trash containers; coconut shells; etc.) by using $0.55 \mathrm{~mm}$ mesh-size fishnets. Mosquito larvae were collected from both indoor and outdoor containers. All live mosquito larvae were placed in plastic bags taken to Walailak University and preserved in $70 \%$ ethanol. Mosquito larvae for Ae. aegypti and Ae. albopictus were identified up to its species level based on Rattanarithikul and Panthusiri's keys (Rattanarithikul and Panthusiri 1994).

In this study, only Ae. aegypti, Ae. albopictus, and Culex mosquito larvae were considered. Mansonia spp., Armigeres spp., and Toxorhynchites spp. larvae were also collected from the field study but constituted less than $1 \%$ of the total number of larvae and were not used. We evaluated the relative abundance of mosquito larvae across 600 households in five subdistricts. We were specifically interested in examining how relative abundance and multiple mosquito species occurrence (co-occurrence at a site) varied with seasons and subdistricts.

\section{Data analysis}

Chi-squared tests were used to investigate the differences in numbers of positive houses, positive containers, containers holding mosquito larvae, containers, and mosquito larvae between the wet and dry seasons and among five subdistricts. Containers with mosquito larvae were classified into eight categories based on types of mosquitoes present in the containers: containers contained (1) Ae. aegypti larvae (AE containers), (2) Ae. albopictus larvae (AL containers), (3) Culex larvae (CX containers), (4) Ae aegypti and Ae. albopictus larvae (AE+AL containers), (5) Ae. aegypti and Culex larvae (AE+CX containers), (6) Ae. albopictus and Culex larvae (AL+CX containers), (7) Ae. aegypti, Ae. albopictus and Culex larvae (AE+AL+CX containers), and (8) no mosquito larvae (negative containers). We used SPSS 22 as the statistical analysis software, and all significant tests were two-tailed. We considered a statistically significant level to be at $P<0.05$.

\section{Results}

Season, positive houses and positive containers

During the wet season, there were higher numbers of positive houses, positive containers, AL containers, and negative containers than during the dry season (Chi-squared test: positive houses: $x_{1}^{2}=22.294, \quad P<0.001$; positive containers: $x_{1}^{2}=10.481, P<0.005 ; \mathrm{AL}$ containers: $x_{1}^{2}=$ 135.905, $P<0.001$; negative containers: $x_{1}^{2}=657.627$, $P<0.001$, Table 1). During the dry season, there were higher numbers of $\mathrm{CX}$ containers, $\mathrm{AE}+\mathrm{CX}$ containers, $\mathrm{AL}+\mathrm{CX}$ containers, and $\mathrm{AE}+\mathrm{AL}+\mathrm{CX}$ containers (Chi-squared test: $\mathrm{CX}$ containers: $x_{1}^{2}=43.758, P<0.001$; $\mathrm{AE}+\mathrm{CX}$ containers: $x_{1}^{2}=$ 21.552, $P<0.001 ; \quad \mathrm{AL}+\mathrm{CX}$ containers: $x_{1}^{2}=17.053$, $P<0.001 ; \mathrm{AE}+\mathrm{AL}+\mathrm{CX}$ containers: $x_{1}^{2}=14.222, P<0.001$, Table 1). Seasons had no effects on numbers of AE containers and $\mathrm{AE}+\mathrm{AL}$ containers (Chi-squared test: $\mathrm{AE}$ containers: $x_{1}^{2}=0.602, n s ; \mathrm{AE}+\mathrm{AL}$ containers: $x_{1}^{2}=1.704, n s$, Table 1$)$.

\section{Subdistricts, positive houses, and positive containers}

Among subdistricts, there were some differences in numbers of positive containers, AE containers, AL containers, $\mathrm{AE}+\mathrm{AL}$ containers, and negative containers (Chi-squared test: positive containers: $\quad x_{4}^{2}=79.707, \quad P<0.001 ; \quad \mathrm{AE}$ containers: $x_{4}^{2}=15.807, \quad P<0.005 ; \quad \mathrm{AL}$ containers: $x_{4}^{2}=$ 47.546, $\quad P<0.001 ; \quad \mathrm{AE}+\mathrm{AL} \quad$ containers: $x_{4}^{2}=20.197$, $P<0.001$; negative containers: $x_{4}^{2}=160.836, P<0.001$, Table 1). There was no difference among subdistricts in numbers of positive houses, $\mathrm{CX}$ containers, $\mathrm{AE}+\mathrm{CX}$ containers, $\mathrm{AL}+\mathrm{CX}$ containers, and $\mathrm{AE}+\mathrm{AL}+\mathrm{CX}$ containers (Chi-squared test: positive houses: $x_{4}^{2}=8.298, n s ; \mathrm{CX}$ containers: $x_{4}^{2}=6.485$, $n s$; AE $+\mathrm{CX}$ containers: $x_{4}^{2}=5.310, n s ; \mathrm{AL}+\mathrm{CX}$ containers: $x_{4}^{2}=6.368, n s ; \mathrm{AE}+\mathrm{AL}+\mathrm{CX}$ containers: $x_{4}^{2}=4.222, n s$, Table 1).

\section{Seasons and numbers of mosquito larvae}

From a total of 1,072 positive containers collected in both seasons, Ae. albopictus larvae were found in the highest number of containers (745 AL containers), followed by containers with Ae. aegypti larvae (283 AE containers) and containers with Culex larvae (254 CX containers) (Chisquared test: $\left.x_{2}^{2}=355.200, P<0.001\right)$. From a total of 15,783 mosquito larvae collected in both seasons, Ae. albopictus larvae were found in the highest number (10,269 larvae), followed by Culex larvae (2,996 larvae) and Ae. aegypti larvae (2,518 larvae) (Chi-squared test: $\left.x_{2}^{2}=7172.465, P<0.001\right)$. 
Table 1 Seasons and subdistricts with positive $(+)$ houses and positive $(+)$ containers occupied by Ae. aegypti (AE), Ae. albopictus (AL), and Culex (CX) larvae during the wet and dry seasons five subdistricts, Nakhon Si Thammarat, Thailand.

\begin{tabular}{|c|c|c|c|c|c|c|c|c|c|c|c|c|c|c|c|c|c|}
\hline \multirow[t]{2}{*}{ Parameters } & \multicolumn{3}{|c|}{ Khaokaew } & \multicolumn{3}{|c|}{ Lansaka } & \multicolumn{3}{|c|}{ Thadi } & \multicolumn{3}{|c|}{ Kamlon } & \multicolumn{3}{|c|}{ Khunthale } & \multicolumn{2}{|c|}{ Total } \\
\hline & Dry & Wet & Total & Dry & Wet & Total & Dry & Wet & Total & Dry & Wet & Total & Dry & Wet & Total & Dry & Wet \\
\hline+ House & 22 & 31 & 53 & 21 & 31 & 52 & 29 & 51 & 80 & 19 & 41 & 60 & 22 & 42 & 64 & 113 & 196 \\
\hline +Container & 131 & 93 & 224 & 73 & 68 & 141 & 132 & 186 & 318 & 75 & 113 & 188 & 72 & 129 & 201 & 483 & 589 \\
\hline $\mathrm{AE}$ & 26 & 15 & 41 & 14 & 7 & 21 & 21 & 28 & 49 & 15 & 12 & 27 & 12 & 16 & 28 & 88 & 78 \\
\hline $\mathrm{AL}$ & 40 & 58 & 98 & 21 & 55 & 76 & 40 & 136 & 176 & 26 & 90 & 116 & 23 & 92 & 115 & 150 & 431 \\
\hline $\mathrm{CX}$ & 28 & 8 & 36 & 17 & 3 & 20 & 26 & 4 & 30 & 17 & 5 & 22 & 16 & 8 & 24 & 104 & 28 \\
\hline $\mathrm{AE}+\mathrm{AL}$ & 13 & 5 & 18 & 6 & 1 & 7 & 12 & 15 & 27 & 4 & 3 & 7 & 6 & 6 & 12 & 41 & 30 \\
\hline $\mathrm{AE}+\mathrm{CX}$ & 6 & 1 & 7 & 5 & 0 & 5 & 10 & 0 & 10 & 3 & 0 & 3 & 3 & 1 & 4 & 27 & 2 \\
\hline $\mathrm{AL}+\mathrm{CX}$ & 13 & 6 & 19 & 7 & 2 & 9 & 18 & 3 & 21 & 9 & 3 & 12 & 9 & 6 & 15 & 56 & 20 \\
\hline $\mathrm{AE}+\mathrm{AL}+\mathrm{CX}$ & 5 & 0 & 5 & 3 & 0 & 3 & 5 & 1 & 6 & 1 & 0 & 1 & 3 & 0 & 3 & 17 & 1 \\
\hline None & 98 & 263 & 361 & 103 & 332 & 435 & 121 & 556 & 677 & 114 & 345 & 459 & 87 & 248 & 335 & 523 & 1744 \\
\hline
\end{tabular}

During the dry season, a total of 483 positive containers were found with a total of 6,165 mosquito larvae found in those containers, while during the wet season, a total of 589 positive containers were found with 9,618 mosquito larvae. During the dry season, there were higher numbers of $\mathrm{CX}$, $\mathrm{AE}+\mathrm{AL}, \mathrm{AE}+\mathrm{CX}, \mathrm{AL}+\mathrm{CX}$, and $\mathrm{AE}+\mathrm{AL}+\mathrm{CX}$ larvae but lower numbers of $\mathrm{AE}$ and AL larvae than during the wet season (Table 2).

\section{Discussion}

There has been extensive research conducted on the coexistence of mosquito species in the same breeding sites in the US, Columbia, and Italy. Examples of such coexistence include Ae. albopictus and Cx. quinquefasciatus (Daniels et al
2015), Ae. albopictus and Ae. triseriatus (Novak et al 1993), Ae. albopictus and Cx. pipiens (Hawley 1988; Vinogradova 2000; Carrieri et al 2003, 2011; Costanzo et al 2005; Marini et al 2017), and Ae. aegypti and Cx. quinquefasciatus (SantanaMartínez et al 2017). Our results were the first to report the coexistence of Ae. aegypti, Ae. albopictus and Culex larvae in the same breeding sites in Thailand. We showed that not only Ae. aegypti and Ae. albopictus larvae coexisted in the same containers but also coexisted with Culex larvae in those same containers. Coexistence of Aedes and Culex larvae has been found in the same breeding containers, such as flower pots, animal pans, drums, used tires, buckets, flower saucers, tarpaulins, manholes, and bathtubs (Carrieri et al 2003; Leisnham et al 2014).

Table 2 Numbers of mosquito larvae during the wet and dry seasons in five subdistricts, Nakhon Si Thammarat, Thailand.

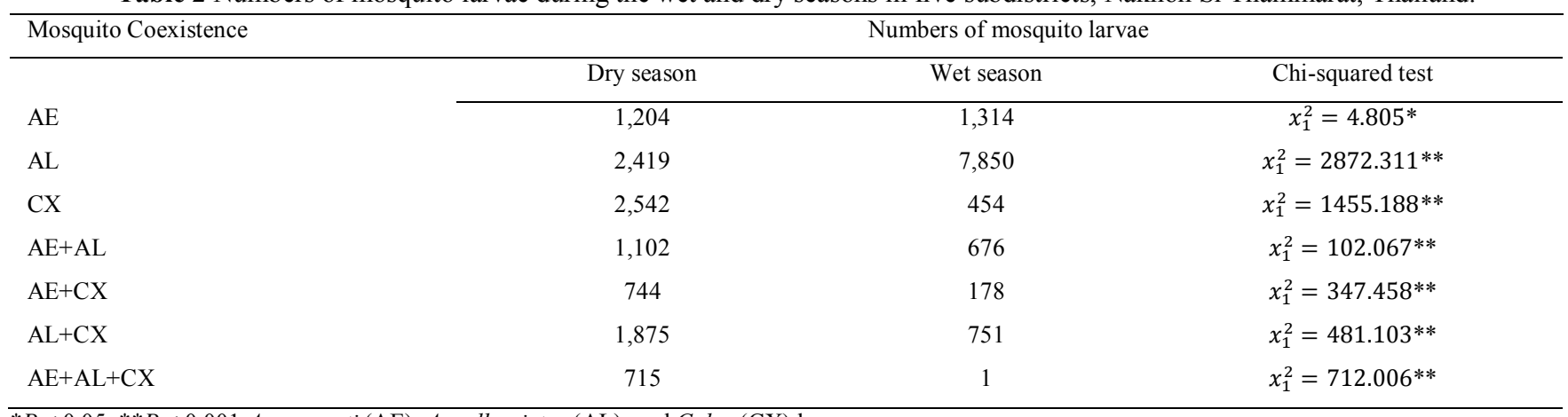

${ }^{*} P<0.05,{ }^{* *} P<0.001$ Ae. aegypti (AE), Ae. albopictus (AL), and Culex (CX) larvae.

The results of this study showed a clear pattern in the seasonal coexistence of Ae. albopictus, Ae. aegypti, and Culex larvae that were consistent with the seasonal conditionspecific competition as the mechanism contributing to species coexistence. The persistence of Ae. albopictus larvae in the presence of the competitively superior Ae. aegypti and Culex larvae may be explained by the seasonal condition-specific competition, if there are seasonally-related differences in survival among the species. Our results showed that during the wet season when mosquito breeding sites were highly abundant, the majority of mosquito breeding sites were occupied with only Ae. albopictus larvae indicating the superior competitor to other mosquito species. On the other hand, during the dry season, mosquito breeding sites became 
very scarce forcing Ae. aegypti and Culex females to have no other choice but to lay eggs in containers where Ae. albopictus larvae already occupied. Our results showed that there were higher numbers of mosquito breeding sites occupied with more than one mosquito species during the dry season than during the wet season. Leisnham and Juliano (2009) found that Ae. albopictus was usually superior in competition to Ae. aegypti, and these species coexist at some sites in the southeastern part of the United States, including metropolitan areas. Ae. albopictus larvae would show a greater increase in the proportion of sites occupied and abundance per site during the wet season than Culex and Ae. aegypti larvae due to their high dry season egg mortality and strong wet season competitive superiority.

Our results showed that the number of Ae. aegypti and Ae. albopictus larvae were higher than Culex larvae during the wet season. Similar findings were reported by Lin et al (2018) in Taiwan. This could be due to two possible reasons. First, Ae. aegypti larvae were found mostly in indoor containers, but Culex larvae were mostly found in outdoor containers. Usually, outdoor containers are affected by rainwater during the wet season as rainfall flushes out the mosquito larvae from the outdoor containers. Second, during the wet season, normally the water inside outdoor containers stays clean due to frequent rainfall. Typically, Culex mosquitoes do not prefer to lay eggs in clean water, whereas Ae. albopictus larvae are generally found in outdoor containers with clean water (Chumsri et al 2018).

The number of Ae. albopictus larvae during the wet season was higher than during the dry season. Normally $A e$. albopictus mosquitoes like to lay their eggs in outdoor containers. During the wet season, higher numbers of total containers were observed in all subdistricts. A previous study (Chumsri et al 2018) also observed a higher number of total containers during the wet season than during the dry season in Lansaka District. There are two possible reasons for a higher number of total containers during the wet season: (1) people in Southern Thailand prefer to use rainwater for cooking, bathing, and other purposes, and for these reasons they use a higher number of various types of containers to collect rainwater (Wongkoon et al 2007; Chumsri et al 2018) and (2) waste products, such as Styrofoam cups, bottles, used cans and used tires, might collect rainwater, creating many suitable larval development sites for Ae. albopictus larvae in the area.

Our results showed a higher number of Culex larvae during the dry season than during the wet season. Similar findings were reported in Nigeria (Mahadev et al 2004), India (Govoetchan et al 2014), and Benin (Manyi et al 2014). This could happen due to four possible reasons. First, during the dry season, there is typically a lack of fresh water, and thus, water is stored in one container for a long period without cleaning it. In contrast, rainwater during the wet season flushes out the stored water in containers more often.
Therefore, during the dry season, Culex larvae have a higher chance to stay in the same water for a longer period and finish their larval stages compared to during the wet season. Second, Culex mosquitoes prefer to breed in stagnant water with high organic matter in outdoor containers (Preechaporn et al 2007). These favorable breeding sites are high in numbers during the dry season. Third, oviposition activity of Culex females increases if relative humidity becomes $60 \%$ or higher (Micieli and Campos 2003), and during the period of this study, the average humidity of our study sites was more than $80 \%$ (data collected by our automatic weather station deployed at the site). Fourth, higher temperatures during the dry season in southern Thailand may shorten the rates of embryonic, larval and pupal development stages of mosquitoes, which leads to a higher number of smaller-sized females that digest blood more often and produce more offspring (Githeko et al 2000; Promprou et al 2005; Kiarie-Makara et al 2015). Madder et al (1983) reported that $C x$. pipiens and $C x$. restuans in Ontario had three major generations per year. This indicates that a higher temperature during the dry season might increase the number of generations per year. The estimated optimal temperature for Culex mosquito developmental stages is $28.1^{\circ} \mathrm{C}$ (Loetti et al 2011; Kiarie-Makara et al 2015), and the average temperature during the dry season in Southern Thailand is $28.2^{\circ} \mathrm{C}$.

Our results support the spatial hypothesis that the cooccurrence of larval species was found in all five subdistricts and Ae. albopictus larvae were more competitive compared to Ae. aegypti and Culex larvae in all five subdistricts. When we compared the number of positive houses, positive containers and the number of $\mathrm{AE}, \mathrm{AL}, \mathrm{CX}, \mathrm{AE}+\mathrm{AL}, \mathrm{AE}+\mathrm{CX}, \mathrm{AL}+\mathrm{CX}$, and $\mathrm{AE}+\mathrm{AL}+\mathrm{CX}$ containers among five subdistricts, we found that Khaokaew and Thadi subdistricts were higher in all these parameters than other subdistricts during the wet and dry seasons. This could be due to four possible reasons. First, Ae. aegypti larvae are found mostly in indoor containers. During the dry season, a higher number of containers were observed in Khaokaew and Thadi subdistricts than in other subdistricts because people in these subdistricts do not have sustainable water supplies and collect water from the nearby river. This was why they used a higher number of water-storing containers during the dry season; evidently, many people did not frequently clean their water-storing containers throughout the dry season. Secondly, the people in Lansaka District planted fruits (e.g. durians, mangosteens, and jackfruits) as their main occupation and some households in Khaokaew and Thadi subdistricts liked to water their fruits by placing a water container under their fruit tree, making it a key breeding site for Ae. albopictus to lay their eggs. Third, Thadi people preferred to keep a higher number of plant pots around their houses. Besides, the Thadi Administration Organisation does not provide rubbish/waste collection services in this subdistrict, and thus, Thadi people need to clean their 
rubbish/waste by themselves; they do so by burning their trash outdoors. During the dry season, it is easier for them to burn the waste more often compared to during the wet season, as rainwater makes the waste too wet to be burned. Fourth, Khaokaew people have the habit of using and throwing away a higher amount of refuse around their house.

\section{Conclusions}

Competitive interactions between Ae. aegypti, Ae. albopictus and Culex spp. in Southern Thailand are asymmetrical when they coexist in nature. The seasonal condition-specific competition is the mechanism contributing to species coexistence. With high competitive asymmetry, the competitive inferior species shift their temporal patterns to lower interspecific competition. During the wet season, when breeding sites are highly abundant, the majority of breeding sites are occupied with only Ae. albopictus larvae (superior competitor). In contrast, during the dry season when breeding sites become very scarce, inferior species (Ae. aegypti and Culex spp.) have no other choice but to lay eggs in containers where Ae. albopictus larvae already occupy.

\section{Acknowledgments}

This manuscript was funded in part by a grant from the United States Department of State. The opinions, findings, and conclusions stated herein are those of the authors and do not necessarily reflect those of the United States Department of State. We would like to thank Tony Murphy, Mindi DePaola, David Chang, and the referees for comments on previous versions of this manuscript. The authors are grateful to Chumpon Polprasert and his team from the Lansaka District Health Office for their help during field surveys. This work was supported by the Centre of Excellence for Ecoinformatics, the Institute of Research and Innovation, Walailak University.

\section{Conflict of Interest}

The authors declare no conflict of interest.

\section{References}

Armistead JS, Arias JR, Nishimura N, Lounibos LP (2008) Interspecific larval competition between Aedes albopictus and Aedes japonicus (Diptera: Culicidae) in northern Virginia. Journal of Medical Entomology 45:629-637.

Barrera R (1996) Competition and resistance to starvation in larvae of container- inhabiting Aedes mosquitoes. Ecological Entomology 21:117-127.

Becker N, Petric D, Zgomba M, Boase C, Madon M, Dahl C, Kaiser A (2010) Mosquitoes and their control. Springer Science and Business Media, NY.

Braks MAH, Honório NA, Lounibos LP, Lourenço-de-Oliveira R, Juliano SA (2004) Interspecific competition between two invasive species of container mosquitoes, Aedes aegypti and Aedes albopictus
(Diptera: Culicidae), in Brazil. Annals of the Entomological Society of America 97:130-139.

Carrieri M, Albieri A, Angelini P, Baldacchini F, Venturelli C, Zeo SM, Bellini R (2011) Surveillance of the chikungunya vector Aedes albopictus (Skuse) in Emilia- Romagna (northern Italy): Organizational and technical aspects of a large scale monitoring system. Journal of Vector Ecology 36:108-116.

Carrieri M, Bacchi M, Bellini R, Maini S (2003) On the competition occurring between Aedes albopictus and Culex pipiens (Diptera: Culicidae) in Italy. Environmental Entomology 32:1313-1321.

Chansang J, Paosriwong S, Benjaphong N, Thavara U, Chansang U (1999) Aedes survey at dengue haemorrhagic fever case villages in northern region. Journal of Health Science 8:52-63.

Chareonviriyaphap T, Prabaripai A, Bangs MJ, Aum-Aung B (2003) Seasonal abundance and blood feeding activity of Anopheles minimus Theobald (Diptera: Culicidae) in Thailand. Journal of Medical Entomology 40:876-881.

Chumsri A, Tina FW, Jaroensutasinee M, Jaroensutasinee K (2018) Seasons and socio-cultural practices affecting Aedes mosquito larvae in southern Thailand. Tropical Biomedicine 35:111-125.

Costanzo KS, Mormann K, Juliano, SA (2005) Asymmetrical competition and patterns of abundance of Aedes albopictus and Culex pipiens (Diptera: Culicidae). Journal of Medical Entomology 42:559570.

Daniels S, Ezeakacha NF, Yee DA (2015) Interspecific interactions between adult Aedes albopictus and Culex quinquefasciatus (Diptera: Culicidae). Journal of Medical Entomology 53:466-469.

Daugherty MP, Alto BW, Juliano SA (2000) Invertebrate carcasses as a resource for competing Aedes albopictus and Aedes aegypti (Diptera: Culicidae). Journal of Medical Entomology 37:364-372.

Francia A, Maciá A (2017) Effects of larval competition between the container mosquitoes, Aedes aegypti and Culex pipiens (Diptera: Culicidae) in semicontrolled conditions. Revista de la Sociedad Entomológica Argentina 70:305-315.

Githeko AK, Lindsay SW, Confalonieri UE, Patz JA (2000) Climate change and vector-borne diseases: A regional analysis. Bulletin of the World Health Organization 78:1136-1147.

Govoetchan R, Gnanguenon V, Ogouwalé E, Oké-Agbo F, Azondékon R, Sovi A, Attolou R, Badirou K, Youssouf RA, Ossè R, Akogbéto M (2014) Dry season refugia for anopheline larvae and mapping of the seasonal distribution in mosquito larval habitats in Kandi, northeastern Benin. Parasites and Vectors 7:137.

Hawley WA (1988) The biology of Aedes albopictus. Journal of the American Mosquito Control Association 4:1-40.

Ho BC, Ewert A, Chew LM (1989) Interspecific competition among Aedes aegypti, Ae. albopictus, and Ae. triseriatus (Diptera: Culicidae): larval development in mixed cultures. Journal of Medical Entomology 26:615-623.

Juliano SA (2009) Species interactions among larval mosquitoes: Context dependence across habitat gradients. Annual Review of Entomology 54:37-56.

Juliano SA, Lounibos LP, O'Meara GF (2004) A field test for competitive effects of Aedes albopictus on A. aegypti in South Florida: Differences between sites of coexistence and exclusion? Oecologia 139: 583-593.

Kiarie-Makara MW, Ngumbi PM, Lee DK (2015) Effects of temperature on the growth and development of Culex pipiens 
complex mosquitoes (Diptera: Culicidae). IOSR Journal of Pharmacy and Biomedical Sciences 10:1-10.

Leisnham PT, Juliano SA (2009) Spatial and temporal patterns of coexistence between competing Aedes mosquitoes in urban Florida. Oecologia 160:343-352.

Leisnham PT, LaDeau SL, Juliano SA (2014) Spatial and temporal habitat segregation of mosquitoes in urban Florida. PloS one 9:e91655.

Lin CH, Schiøler KL, Ekstrøm CT, Konradsen (2018) Location, seasonal, and functional characteristics of water holding containers with juvenile and pupal Aedes aegypti in Southern Taiwan: A crosssectional study using hurdle model analyses. PLoS Neglected Tropical Diseases 12:e006882.

Loetti V, Schweigmann NJ, Burroni NE (2011) Temperature effects on the immature development time of Culex eduardoi Casal \& García (Diptera: Culicidae). Neotropical Entomology 40:138-142.

Luemoh A, McNeil D, Kuning M (2003) Water consumption and distribution of dengue larvae in Pattani villages. Songkhlanakarind Medical Journal 21:209-212.

Madder DJ, Surgeoner GA, Helson BV (1983) Number of generations, egg production and developmental time of Culex pipiens and Culex restuans (Diptera: Culicidae) in southern Ontario. Journal of Medical Entomology 20:275-287.

Mahadev PVM, Fulmali PV, Mishra AC (2004) A preliminary study of multilevel geographic distribution and prevalence of Aedes aegypti (Diptera: Culicidae) in the state of Goa. The Indian Journal of Medical Research 120:173-182.

Manyi MM, Vajime CG, Imandeh GN (2014) Seasonal changes of microfilarial infection and infectivity rates in mosquito populations within Makurdi, Benue State, Nigeria. International Journal of Mosquito Research 1:1-9.

Marini G, Guzzetta G, Baldacchino F, Arnoldi D, Montarsi F, Capelli G, Rizzoli A, Merler S, Rosà R (2017) The effect of interspecific competition on the temporal dynamics of Aedes albopictus and Culex pipiens. Parasites and Vectors 10:102.

Micieli MV, Campos RE (2003) Oviposition activity and seasonal pattern of a population of Aedes (Stegomyia) aegypti (L.) (Diptera: Culicidae) in subtropical Argentina. Memórias do Instituto Oswaldo Cruz 98:659-663.

Murrell EG, Juliano SA (2008) Detritus type alters the outcome of interspecific competition between Aedes aegypti and Aedes albopictus (Diptera: Culicidae). Journal of Medical Entomology 45:375-383.

Muturi EJ, Lampman R, Costanzo K, Alto BW (2011) Effect of temperature and insecticide stress on life-history traits of Culex restuans and Aedes albopictus (Diptera: Culicidae). Journal of Medical Entomology 48:243-250.
Novak MG, Higley LG, Christianssen CA, Rowley WA (1993) Evaluating larval competition between Aedes albopictus and Ae. triseriatus (Diptera: Culicidae) through replacement series experiments. Environmental Entomology 22:311-318.

Preechaporn W, Jaroensutasinee M, Jaroensutasinee K (2006) The larval ecology of Aedes aegypti and Ae. albopictus in three topographical areas of Southern Thailand. Dengue Bulletin 30:204213.

Preechaporn W, Jaroensutasinee M, Jaroensutasinee K, Saeton J (2007) Seasonal and topographical factors affecting breeding sites of Culex larvae in Nakhon Si Thammarat, Thailand. Walailak Journal of Science and Technology 4:23-39.

Promprao S, Ratmanee Y, Kaikaew J (2018) Ecology of Aedes mosquitoes in Kreang Sub-District, Cha-Uat district, Nakhon Si Thammarat. Thaksin University Journal 21:9-20.

Promprou S, Jaroensutasinee, M, Jaroensutasinee K (2005). Climatic factors affecting dengue haemorrhagic fever incidence in southern Thailand. Dengue Bullitin 29:41-48.

Rattanarithikul R, Panthusiri P (1994) Illustrated keys to the medically important mosquitoes of Thailand. Southeast Asian Journal of Tropical Medicine and Public Health 25:1-66.

Santana-Martínez J, Molina J, Dussán J (2017) Asymmetrical competition between Aedes aegypti and Culex quinquefasciatus (Diptera: Culicidae) coexisting in breeding sites. Insects 8:111.

Scanlon JE, Esah S (1965) Distribution in altitude of mosquitoes in northern Thailand. Mosquito News 25:137-144.

Serpa LLN, Kakitani I, Voltolini JC (2008) Competição entre larvas de Aedes aegypti e Aedes albopictus em laboratório. The Journal of the Brazilian Society of Tropical Medicine 41:479-484.

Thanispong K, Sathantriphop S, Chareonviriyaphap T (2008) Insecticide resistance of Aedes aegypti and Culex quinquefasciatus in Thailand. Journal of Pesticide Science 33:351-356.

Thavara U, Tawatsin A, Chompoosri J (2004) Evaluation of attractants and egg-laying substrate preference for oviposition by Aedes albopictus (Diptera: Culicidae). Journal of Vector Ecology 29:66-72.

Vinogradova EB (2000) Culex pipiens pipiens mosquitoes; taxonomy, distribution, ecology, physiology, genetics, applied importance and control. Pensoft, Sofia, Bulgaria.

Wongkoon S, Jaroensutasinee M, Jaroensutasinee K, Preechaporn W (2007) Development sites of Aedes aegypti and Aedes albopictus larvae in Nakhon Si Thammarat, Thailand. Dengue Bulletin 31:14152.

Yee DA, Skiff JF (2014) Interspecific competition of a new invasive mosquito, Culex coronator, and two container mosquitoes, Aedes albopictus and Cx. quinquefasciatus (Diptera: Culicidae), across different detritus environments. Journal of Medical Entomology 51:89-96. 